Disponível em:

http://editora.unoesc.edu.br/index.php/race

RACE, Joaçaba, v. 16, n. 2, p. 547-572, maio/ago. 2017

\title{
CAPITAL SOCIAL E TURISMO RURAL EM UMA ASSOCIAÇÃO DO NORTE DO RIO GRANDE DO SUL: UM ESTUDO DA ROTA DAS SALAMARIAS
}

Social capital and rural tourism in an Association of the Northern Rio Grande do Sul: a study in Rota das Salamarias

Jaqueline dos Santos

E-mail: jaque_s2004@yahoo.com.br Mestre em Administração pela Faculdade Meridional; Pós-graduada em Gestão de Pessoas pela Faculdade Anhanguera; Assistente em Administração no Instituto Federal Sul-Rio-Grandense. Endereço para contato: Estrada Perimetral Leste, 150, 99064-440, Passo Fundo, Rio Grande do Sul; Brasil.

\begin{abstract}
Fabiana Melara
E-mail: fabiana@forzacom.com.br Mestre em Administração pela Faculdade Meridional; Pós-graduada em Gestão de Pessoas pela Faculdade Meridional; Sócia na agência de publicidade Felicità.
\end{abstract}

Eliana Andréa Severo

E-mail: eliana.severo@imed.edu.br Doutora em Administração pela Pontifícia Universidade Católica do Rio Grande do Sul e pela Universidade de Caxias do Sul; Mestre em Administração pela Universidade de Caxias do Sul; Professora na Faculdade Meridional.

Janaina Macke

E-mail: janaina.macke@imed.edu.br Doutora em Administração pela Universidade Federal do Rio Grande do Sul; Mestre em Engenharia de Produção pela Universidade Federal do Rio Grande do Sul;

Professora na Faculdade Meridional. 


\section{Resumo}

O capital social é a soma dos recursos reais e potenciais de uma rede de relacionamentos de uma unidade individual ou social. O objetivo com a presente pesquisa foi entender como o capital social contribui para o desenvolvimento do turismo rural na Associação Rota das Salamarias, localizada na região Norte do Rio Grande do Sul. A pesquisa caracteriza-se como qualitativa, tendo como abordagem o estudo de caso, e quanto ao propósito pode ser definida como descritiva. Para a coleta de dados realizaram-se entrevistas semiestruturadas. Posteriormente, as entrevistas foram integralmente transcritas e realizou-se análise de conteúdo. Entre os principais resultados obtidos se destaca o fato de o turismo rural ser uma estratégia de desenvolvimento local que contribui para a geração de renda e para a manutenção das famílias em suas propriedades, fortalece o empreendedorismo familiar e amplia a relação entre as famílias que compõem a Rota. Também, identificou-se a relevância do crescimento econômico e do capital social reconhecido no formato de interação social proporcionado pela referida Associação, visto que essa coesão social fundamenta a construção de vantagens competitivas sustentáveis, dado que o conhecimento é adquirido e transmitido a todos que fazem parte da rede de parceiros, gerando riquezas para as propriedades e para a região da qual fazem parte. Palavras-chave: Capital social. Turismo rural. Associação Rota das Salamarias. Vantagens competitivas.

\section{Abstract}

Social capital is the sum of the actual and potential resources of a network of relationships of individual or social unit. The aim of this research was to understand how the social capital contributes for the development of rural tourism in Rota das Salamarias. The research is characterized as qualitative, with the approach of the case study, and regarding the purpose it can be defined as descriptive. For data collection semi-structured interviews were carried out. Subsequently, the interviews were fully transcribed and the content analysis was performed. Among the main findings stands out the fact that rural tourism is a local development strategy that contributes for the income generation and for the maintenance of families in their properties, strengthens the family entrepreneurship and expands the relationship between the families that make up the route. Also, it was identified the importance of economic growth and the social capital recognized in the interaction format provided by that Association, since this social cohesion supports the building of the sustainable competitive advantages, since knowledge is acquired and transmitted to everyone who is part of the network of partners, generating wealth for the properties and for the region to which they belong.

Keywords: Social capital. Rural tourism. Association Rota das Salamarias. Competitive advantages. 


\section{INTRODUÇÃO}

O capital social é fundamental para o desenvolvimento sustentável da sociedade, visto que para a presente pesquisa ele foi considerado como a soma dos recursos reais e potenciais de uma rede de relacionamentos de uma unidade individual ou social. O capital social possibilita competir com sucesso e potencializa a capacidade individual e coletiva mediante as práticas colaborativas, o que viabiliza a realização de objetivos que não seriam alcançados de outra forma (NAHAPIET; GHOSHAL, 1998; FACCIN et al., 2009; WORLD BANK, 2015).

Segundo Moscardo (2012), uma das áreas pela qual a ligação entre o turismo e o capital social pode ser analisada diz respeito às implicações das atividades de negócios turísticos para o capital social e às considerações sobre o papel do capital social nas relações entre turismo e desenvolvimento regional periférico ou rural, discutindo-se as interações entre o desenvolvimento do turismo e do capital social. O capital social decorrente de empreendimentos turísticos eficazes pode contribuir de forma significativa para a melhoria da qualidade de vida de todos os envolvidos.

O capital social em comunidades de turismo rural é um estoque, por natureza, uma propensão para a ação coletiva mutuamente benéfica, que algumas comunidades de turismo possuem em maior medida do que outras (PARK et al., 2012).

O turismo rural, por sua vez, possibilita agregar valor aos produtos e serviços oferecidos pela comunidade bem como promover a cultura e a paisagem do local, além de fornecer ao agricultor uma fonte de renda complementar (DEL GROSSI; SILVA, 2002; BRUNETTI, 2006; BRASIL, 2003; 2007; OLIVEIRA; ZOUAIN, 2011).

No Brasil, as primeiras propriedades rurais abertas à visitação teriam surgido em 1986, em Lages, Santa Catarina, caracterizando o Turismo Rural como oportunidade para a busca de alternativas frente às dificuldades que o setor agropecuário enfrentava (MINISTÉRIO DO TURISMO, 2010).

Uma gama de conceitos está ligada ao turismo rural, como turismo de interior, agroturismo, turismo alternativo, endógeno, turismo verde, ecoturismo, turismo de rotas agrícolas, roteiros ou circuitos no meio rural, pesque-pague, entre outros. Para fins da presente pesquisa, o turismo rural constitui-se da prática de toda maneira turística de visitar e conhecer o ambiente rural, enquanto é valorizada e resgatada a cultura regional. Trata-se de uma atividade que se integra às atividades agropecuárias cotidianas da propriedade rural que podem ser ao mesmo tempo atrações turísticas e fontes de renda para os produtores (ROQUE; VIVAN, 1999). 
O desenvolvimento do turismo rural por meio de associações pode ser uma estratégia na busca pela satisfação das demandas sociais locais frente às políticas públicas e a um cenário de competitividade que requer produtos/serviços e estratégias compatíveis com esses novos padrões (ROQUE; VIVAN, 1999; TEIXEIRA; SOUZA; ROBE, 2012). Pode-se citar aqui exemplos já estudados e publicados de associações da Serra Gaúcha, como, por exemplo, a Associação dos Produtores de Vinhos Finos do Vale dos Vinhedos (Aprovale) e a Associação dos Vitivinicultores de Monte Belo do Sul (Aprobelo), em que o resultado das pesquisas indicou que o capital social facilita a cooperação e melhora a eficiência (FACCIN; GENARI; MACKE, 2013).

Portanto, a proposta com a presente pesquisa foi responder à questão: como o capital social contribui para o desenvolvimento do turismo rural na Rota das Salamarias? Com este estudo teve-se por objetivo entender como o capital social contribui para o desenvolvimento do turismo rural na Rota das Salamarias. Para isso, buscou-se identificar as principais motivações e benefícios para a participação na associação, verificar como é a relação das famílias participantes, identificar como acontece a qualificação e o aperfeiçoamento dos associados e quais são seus projetos futuros e, por fim, verificar as percepções dos participantes sobre a associação e as dificuldades enfrentadas.

Para alcançar os objetivos mencionados, foi analisada a Associação Rota das Salamarias na região Norte do Rio Grande do Sul, a qual teve início no ano 2008 com o incentivo do Poder Público Municipal da Cidade de Marau, onde a Rota fica localizada, sendo composta por 12 propriedades, com uma extensão aproximada de $13 \mathrm{~km}$, que se preparam para receber turistas e complementar sua renda. Uma das propriedades oferece passeios guiados, e em todas são vendidos produtos de fabricação própria, além de alguns itens produzidos pelos demais integrantes da Rota. A relevância do estudo deve-se ao fato de o turismo rural ser visto como estratégia de desenvolvimento local.

\section{REFERENCIAL TEÓRICO}

\subsection{CAPITAL SOCIAL}

O tema capital social geralmente é tratado na literatura partindo-se do pressuposto de que as variáveis econômicas não são suficientes para o desenvolvimento social e para a construção de um ambiente sustentável (FACCIN et al., 2009). 
O capital social refere-se às instituições, relações e normas que moldam a qualidade e a quantidade de interações sociais de uma sociedade, não é apenas a soma das instituições que sustentam uma sociedade, é a cola que as une, visto que a coesão social é fundamental para que as sociedades prosperem economicamente e para que o desenvolvimento seja sustentável (WORLD BANK, 2015).

Os participantes de uma rede podem construir vantagens competitivas sustentáveis, não apenas confiando em seu capital social, mas também no capital social de outras empresas, organizações e instituições. O capital social é um dos principais constituintes da Organização em rede, na qual as relações são privilegiadas, pois são capazes de transmitir o conhecimento tácito que está incorporado em competências essenciais e capacidades essenciais. Relações com outras empresas e organizações geralmente transmitem somente o conhecimento explícito, que é menos relevante para o processo de obter e manter vantagens competitivas. Nesse sentido, o capital social pertencente a outra rede será classificado menor do que o capital social dentro da rede (MARTI, 2004).

Segundo Nahapiet e Ghoshal (1998), o capital social pode ser analisado por meio de três dimensões altamente inter-relacionadas: dimensão estrutural: relacionada com padrão geral de conexão entre os atores; dimensão relacional: ativos criados e alavancados por meio das relações; e dimensão cognitiva: remete a recursos que representam visões compartilhadas, interpretações e sistemas de significados como linguagem, códigos e narrativas.

Embora nem todas as dimensões do capital social se reforcem mutuamente, a dimensão estrutural do capital social influencia o desenvolvimento da dimensão relacional e cognitiva, de modo que o capital social pode produzir riqueza para a organização, possibilitando a realização de atividades, que apenas seriam possíveis sozinhas a custos mais elevados (NAHAPIET; GHOSHAL, 1998).

O capital social dirige comportamentos de moradores por meio de normas, regras e valores da comunidade, como um meio para alcançar a sustentabilidade em longo prazo, e pode ser mutuamente benéfico para os moradores e para o ambiente. Nesse sentido, o capital social estrutural enfatiza as normas e regras da comunidade, enquanto o capital social cognitivo inclui valores, atitudes e crenças; o capital social cognitivo, em particular, poderia servir como um mediador para a relação entre benefícios econômicos e comportamentos pró-ambientais da comunidade (LIU et al., 2014).

Conforme Zhao, Ritchie e Echtner (2011), a dimensão estrutural do capital social tem um impacto significativo na disponibilidade de recursos como capital, es- 
paço, instalações, equipamentos e mão de obra. O capital social relacional é importante para o empreendedorismo porque a experiência pessoal e a qualidade das interações passadas podem influenciar profundamente a quem o membro da rede é susceptível de se aproximar e se envolver com sucesso. E o capital social cognitivo mostra que desenvolver um relacionamento produtivo não apenas requer tempo e compromisso emocional, mas, também, em grande parte, depende da possibilidade ou não de ambos os lados compartilharem algo mentalmente, como valores, atitudes, crenças e visão.

Assim, o capital social pode ser considerado um produto de compromissos mútuos em curso ou ativos de indivíduos, como o processo pelo qual as pessoas se envolvem em relações sociais, a fim de atualizar e perceber os benefícios concomitantes, tratando-se, portanto, de um processo que depende de ações dos atores sociais que são influenciados pela formação estrutural das redes sociais, um capital que o indivíduo pode usar como um recurso em sua prática diária, mas que nunca é realizado a menos que em interação com outros indivíduos em uma rede. Dirige-se, dessa forma, a atenção para as relações sociais e de interação quando se trata de desenvolvimento local (JOHANNESSON; SKAPTADOTTIR; BENEDIKTSSON, 2003).

Em uma comunidade, o capital social parece ser um pré-requisito importante para o desenvolvimento do turismo eficaz e, sob as condições corretas, o desenvolvimento do turismo também pode contribuir para um maior desenvolvimento do capital social, principalmente quando a capacidade de avaliar e construir da comunidade é integrada nos processos de planejamento do turismo (MOSCARDO, 2012). Além disso, o capital social das famílias rurais que participam no negócio de turismo pode ser considerado maior do que o de grupos não participantes (PARK et al., 2012).

Nesse contexto, o capital social pode melhorar a capacidade de uma comunidade gerir de forma sustentável os recursos naturais por meio da geração de normas e regras adequadas e reforçar a confiança e a reciprocidade, as quais lubrificam a cooperação mediante a redução dos custos de transação, pois as pessoas já não têm de investir no monitoramento do comportamento dos outros, construindo, assim, a confiança para investir em atividades coletivas (JONES, 2005).

Dessa forma, o capital social é considerado a soma dos recursos e capacidades que pertencem a uma rede de organizações, possibilitando, dessa forma, competir com sucesso e potencializando a capacidade individual e coletiva mediante as práticas colaborativas, o que viabiliza a realização de objetivos que não seriam alcançados de outra forma (NAHAPIET; GHOSHAL, 1998; FACCIN et al., 2009). Nesse sentido, entende-se que o turismo rural, em forma de associações, é um exemplo de capital social por estas serem constituídas de pessoas que colaboram entre si para alcançarem 
seus objetivos, visando ao aprimoramento de diversos aspectos envolvidos nessa área, como será explorado a seguir.

\subsection{TURISMO RURAL: CARACTERÍSTICAS E POTENCIALIDADES}

A coordenação do Programa de Turismo Rural no Rio Grande do Sul é feita pela Secretaria do Turismo, Esporte e Lazer e prevê a otimização de estruturas, serviços e produtos oferecidos aos visitantes e a divulgação de empreendimentos cadastrados. Em 2007, com a formação do Grupo Gestor de Turismo Rural, as ações de incentivo têm recebido atenção concentrada, visando ao ordenamento e ao fortalecimento do turismo rural gaúcho (BOCK; MACKE, 2011).

No entanto, observa-se que, mesmo um projeto de turismo como o Vale dos Vinhedos, RS, com relevância para o Estado, que serviu como benchmark para a Rota das Salamarias, avança lentamente em direção ao reconhecimento da agricultura familiar como economicamente ativa (SILVEIRA; SALVAGNI, 2014).

Existe uma diversidade de denominações aplicadas às atividades turísticas desenvolvidas no espaço rural que leva à utilização do termo genérico turismo no espaço rural (BRUNETTI, 2006). No caderno de Diretrizes para o Desenvolvimento do Turismo Rural, ele é definido como “o conjunto de atividades turísticas desenvolvidas no meio rural, comprometido com a produção agropecuária, agregando valor a produtos e serviços, resgatando e promovendo o patrimônio cultural e natural da comunidade.” (MINISTÉRIO DO TURISMO, 2003; 2007, p. 11).

Os produtores estão encontrando novas oportunidades a partir da valorização de bens intangíveis que eram pouco considerados, como a paisagem, o lazer e os ritos dos cotidianos agrícola e pecuário e, além disso, as agroindústrias também têm explorado diversos mercados, como, por exemplo, artesanato, doces, bebidas, vinhos, salgados, carnes e derivados, lácteos e derivados (DEL GROSSI; SILVA, 2002).

Entre os aspectos positivos do turismo no espaço rural, pode-se citar a experiência proporcionada aos visitantes; a oportunidade de as famílias locais reverem suas artes locais, símbolos e tradições; o resgate da autoestima dos moradores do interior; a melhora na infraestrutura dos acessos e das propriedades como um todo; a preservação de patrimônios naturais, rurais, culturais e históricos; a geração de empregos e diversificação da renda das famílias; e a melhoria da qualidade de vida (BRUNETTI, 2006; ANDRADE, 2012).

Como exemplos de aspectos negativos se pode mencionar a competição pelo atendimento e comércio para turistas; o abandono das atividades agropecuárias; a 
poluição de modo geral, além de outros possíveis impactos que merecem atenção e monitoramento (BRUNETTI, 2006). A tendência de subordinação das famílias aos mercados competitivos merece igual consideração, uma vez que haverá cobrança pela profissionalização das atividades para atender à expansão do mercado turístico (CANDIOTTO, 2013).

O espaço rural é composto de atividades como agropecuária moderna e atividades não agropecuárias (moradia, lazer, industriais e prestação de serviços), as quais se transformaram em alternativas de emprego e renda no meio rural; visto que essas atividades são cada vez mais valorizadas, tem ocorrido uma crescente urbanização do meio rural (DEL GROSSI; SILVA, 2002).

Nesse contexto, por meio das atividades de turismo rural, o agricultor familiar tem um acréscimo de receita, podendo comercializar diretamente sua produção com os visitantes e promovendo a valorização do seu modo de vida e a conservação dos recursos naturais como forma de reconhecimento da importância dessas pessoas como cidadãos que contribuem para a economia do País (OLIVEIRA; ZOUAIN, 2011).

A necessidade de renda complementar para a sustentabilidade das famílias que mantêm atividade agrícola em pequenas e médias propriedades é consenso e um dos principais motivos para o desenvolvimento do turismo rural. No entanto, a continuidade das atividades agropecuárias das famílias preserva a identidade rural e, também, visto que o turismo pode ser sazonal, torna-se um fluxo irregular de fonte de renda (BRUNETTI, 2006).

Mas, conforme Del Grossi e Silva (2002), com o passar do tempo, no turismo rural é comum que a renda gerada pelos turistas acabe se tornando mais importante que a renda proveniente da atividade agropecuária, e o potencial desse tipo de turismo pode crescer com a conjugação de lazer, história e cultura, visto que para tal crescimento se deve preparar e treinar o pessoal que se destina a atender os turistas.

Portanto, a fim de formalizar esse conjunto de ações coletivas, que se baseiam em visão de longo prazo, requer-se normatização, capacitação e profissionalização do turismo rural, de modo que há risco de esse processo encarecer os produtos turísticos finais e, por isso, uma contrapartida do setor público pode incentivar a sua legalização e a profissionalização (CZAJKOWSKI; CUNHA, 2010; OLIVEIRA; ZOUAIN, 2011; GASCÓN, 2013).

Observou-se nos últimos anos a diminuição da população rural concomitante a um aumento da população urbana, o que pode ser um indicativo de que as atividades das áreas rurais não estariam sendo suficientes para a manutenção das pessoas no campo (Gráfico 1). 
Nesse contexto, a busca por atividades complementares à agricultura torna-se essencial para a permanência das famílias em suas propriedades. Uma das opções para esse fim é o próprio turismo rural, como, por exemplo, a Associação Rota das Salamarias, que contempla 12 propriedades, visto que uma delas está temporariamente desativada por questões de segurança por se tratar de um ecoparque que fica dentro da área de uma usina. As demais produzem e vendem vinho, salame, geleias e chimias, erva-mate, mel, cachaça e artesanato. A pesquisa foi realizada com seis de seus representantes.

Gráfico 1 - População residente no Estado do Rio Grande do Sul, em área urbana e rural, por gênero, nos anos 1940, 1991, 2000 e 2010

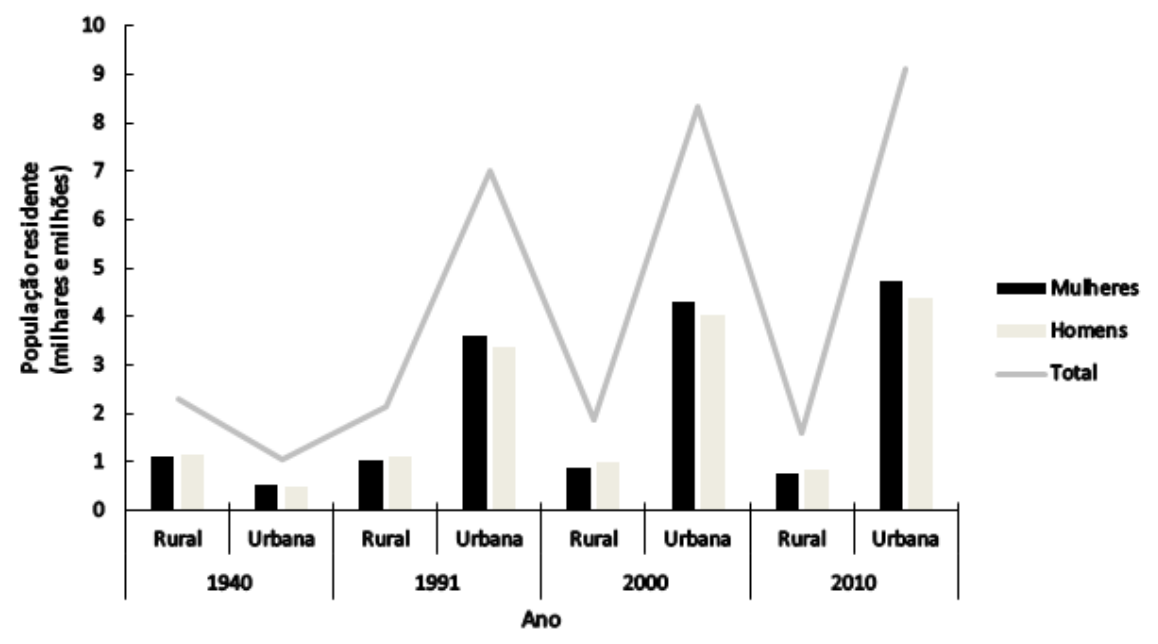

Fonte: adaptado do IBGE (2014).

A Rota das Salamarias está localizada na região Norte do Rio Grande do Sul, na Cidade de Marau, cuja colonização é predominantemente italiana. A primeira empresa que promoveu o desenvolvimento local foi um frigorífico, de propriedade de uma família tradicional da Cidade, época em que recebeu o título de capital nacional do salame. Atualmente, está investindo em atividades de turismo como promotor de renda complementar para as famílias rurais.

\section{MÉTODO}

A presente pesquisa caracteriza-se como qualitativa, a qual, segundo Flick (2009), permite observar diferentes realidades em um mesmo contexto e sob diferen- 
tes perspectivas sociais. Ainda, de acordo com Johannesson, Skaptadottir e Benediktsson (2003), visto que o capital social é um processo ou um efeito de uma prática, é mais proveitoso estudar a sua criação ou manifestação de forma qualitativa, por exemplo, seguindo os atores em suas redes, a fim de entender como as pessoas praticam suas relações sociais.

Entre as diversas abordagens de pesquisa qualitativa, utilizou-se a abordagem de estudo de caso em que, quanto mais as questões buscam explicação para alguma circunstância presente, por exemplo, como ou por que algum fenômeno social funciona, mais o método do estudo de caso será relevante. O estudo de caso também se aplica quando as questões exigem uma descrição ampla e profunda de algum fenômeno social. E, a fim de aumentar a confiabilidade da pesquisa, guiou-se por um protocolo especificamente desenvolvido para isso (YIN, 2010).

Quanto ao propósito, a pesquisa pode ser definida como descritiva, uma vez que busca identificar as situações, atitudes e opiniões manifestas pela população em estudo. Ainda, trata-se de uma coleta de dados do tipo corte-transversal, realizada em um único momento.

Optou-se pela realização de entrevistas semiestruturadas em decorrência da possibilidade de obter dados mais detalhados sobre o ponto de vista de cada entrevistado. Segundo Yin (2010), uma das fontes mais importantes de informação para o estudo de caso é a entrevista, que são conversas guiadas.

Nas entrevistas foi possível perguntar aos entrevistados sobre os fatos de um assunto, bem como suas opiniões sobre os eventos e, em algumas situações, até mesmo solicitar a eles que apresentassem seus próprios insights sobre determinados fatos, obtendo-se, assim, informações sobre o assunto por meio de uma conversa face a face de natureza profissional, realizada de maneira metódica (YIN, 2010; MARCONI; LAKATOS, 2010).

Para a coleta de dados, em um primeiro momento foi elaborado um roteiro de entrevista semiestruturada, com questões fundamentadas em pesquisa bibliográfica e em dados sobre o turismo no Estado do Rio Grande do Sul. Em um segundo momento, as entrevistas foram realizadas com representantes de seis das 12 famílias integrantes da Associação Rota das Salamarias, em um total de seis entrevistados, em sua maioria agricultores, visto que as entrevistas foram realizadas em suas propriedades e gravadas com o consentimento deles, conforme datas e duração mostrados no Quadro 1. Coerentemente, para ampliar a coleta de dados, utilizaram-se diversos documentos como fonte de informação, como relatórios da Associação Rota das Salamarias, documentos administrativos, regulamentos, atas de reunião, recortes de jornais e pareceres (YIN, 2010). 
Quadro 1 - Datas e duração das entrevistas

\begin{tabular}{|c|c|c|}
\hline Entrevistado & Data & Duração (min) \\
\hline E1 & $21 / 08 / 2014$ & 26 \\
\hline E2 & $21 / 08 / 2014$ & 31 \\
\hline E3 & $21 / 08 / 2014$ & 27 \\
\hline E4 & $21 / 08 / 2014$ & 21 \\
\hline E5 & $21 / 08 / 2014$ & 25 \\
\hline E6 & $21 / 08 / 2014$ & 31 \\
\hline
\end{tabular}

Fonte: os autores.

Posteriormente, as entrevistas foram integralmente transcritas e foi realizada a análise de conteúdo. Nesse tipo de análise busca-se explicitar e sistematizar o conteúdo de mensagens e expressões do conteúdo, com índices quantificáveis ou não, efetuando-se deduções lógicas e justificadas, referentes à origem das mensagens, 0 emissor e o seu contexto, ou os efeitos dessas mensagens (BARDIN, 2011). A análise de conteúdo da presente pesquisa foi realizada por meio de categorias de análise, a qual é preconizada positivamente na percepção de Bardin (2011) (Quadro 2).

Quadro 2 - Categorias de análise

\begin{tabular}{|l|l|l|l|}
\hline \multicolumn{1}{|c|}{$\begin{array}{c}\text { Categoria de } \\
\text { análise }\end{array}$} & $\begin{array}{c}\text { Unidade } \\
\text { de análise }\end{array}$ & \multicolumn{1}{|c|}{ Principais questões } & \multicolumn{1}{|c|}{ Autores da temática } \\
\hline $\begin{array}{l}\text { Vantagens e motiva- } \\
\text { ções para participar } \\
\text { da Associação }\end{array}$ & Associado & $\begin{array}{l}\text { Percebe vantagens competitivas nesse } \\
\text { tempo em que faz parte da Rota? } \\
\text { O que mais o motivou a integrar a As- } \\
\text { sociação: conhecer coisas novas; ganhar } \\
\text { competitividade financeira; mostrar/dis- } \\
\text { seminar a tradição e a cultura das famílias } \\
\text { italianas. }\end{array}$ & $\begin{array}{l}\text { Del Grossi eSilva } \\
\text { (2002), } \\
\text { Brunetti (2006), } \\
\text { Faccin et al. (2009), } \\
\text { Andrade (2012) e } \\
\text { Liu et al. (2014). }\end{array}$ \\
\hline $\begin{array}{l}\text { Relação entre as } \\
\text { famílias integrantes }\end{array}$ & Associado & $\begin{array}{l}\text { Todas as famílias convidadas já manti- } \\
\text { nham algum tipo de relação? } \\
\text { Houve algum tipo de "boicote”, insegu- } \\
\text { rança por não conhecer alguma família, } \\
\text { desconfiança por fazer negócios conjun- } \\
\text { tos? } \\
\text { Como classifica a relação entre as famílias } \\
\text { hoje? } \\
\text { O que mudou na relação com a sua fa- } \\
\text { mília? }\end{array}$ & $\begin{array}{l}\text { Nahapiet e Ghoshal } \\
\text { (1998), Faccin et al. } \\
\text { (2009), } \\
\text { Hwang, Stewart e Ko } \\
\text { (2012) e Park et al. } \\
\text { (2012). }\end{array}$ \\
\hline $\begin{array}{l}\text { Qualificação e } \\
\text { aperfeiçoamento } \\
\text { projetos futuros da } \\
\text { Associação }\end{array}$ & Associado \\
\hline $\begin{array}{l}\text { Existe troca de conhecimento entre os } \\
\text { associados? } \\
\text { Participam de cursos de aperfeiçoamento? } \\
\text { Fazem viagens técnicas? } \\
\text { As famílias compartilham projetos futu- } \\
\text { ros? } \\
\text { Existem projetos para implementar a } \\
\text { infraestrutura da Rota como um todo? }\end{array}$ & $\begin{array}{l}\text { Tomazoni (2007), } \\
\text { (2002), Marti (2004), } \\
\text { Brunetti (2006), } \\
\text { Gascón (2013) e Olivei- } \\
\text { ra e Zouain (2011). }\end{array}$ \\
\hline
\end{tabular}




\begin{tabular}{|c|c|c|c|}
\hline $\begin{array}{l}\text { Percepções dos } \\
\text { participantes a } \\
\text { respeito da Associa- } \\
\text { ção e dificuldades } \\
\text { enfrentadas pela } \\
\text { Associação }\end{array}$ & Associado & $\begin{array}{l}\text { Considera que sua propriedade já está } \\
\text { suficientemente organizada para receber } \\
\text { turistas? } \\
\text { A que atribui o sucesso da Rota? } \\
\text { Se saísse hoje da Associação, o que mu- } \\
\text { daria em termos competitivos, de conheci- } \\
\text { mento e qualidade? } \\
\text { O que você e sua família sentem ao, lite- } \\
\text { ralmente, abrir a casa para estranhos? }\end{array}$ & $\begin{array}{l}\text { Nahapiet e Ghoshal } \\
\text { (1998), Roque e Vivan } \\
\text { (1999), Faccin et al. } \\
\text { (2009) e Moscardo } \\
\text { (2012). }\end{array}$ \\
\hline
\end{tabular}

\section{APRESENTAÇÃO E ANÁLISE DOS RESULTADOS}

Os resultados obtidos por meio das entrevistas realizadas com os representantes das propriedades são apresentados e analisados a seguir, de acordo com cada categoria de análise (Quadro 1), buscando-se atender aos objetivos com a presente pesquisa.

Fatores como tradição, hábitos e costumes agregam valor à agricultura familiar, promovendo símbolos e significados às ações, criando características específicas à sua produção e enriquecendo a diversificação das atividades rurais, o que corrobora as assertivas de Silveira e Salvagni (2014).

Na categoria de análise Vantagens e motivações para participar da Associação se verifica que os entrevistados percebem vantagens competitivas pelo fato de participarem da Rota das Salamarias:

[...] eu vejo assim que [...], aqui, a venda triplicou [...] [E2].

[...] aumentou a quantidade de pessoas, de venda [...] [E3].

$[\ldots]$ uma vez eu vendia pouco, [...] mas agora, se a gente fizesse bastante também venderia bastante [...] [E5] (informações verbais).

Percebe-se que pertencer à Associação permite que os participantes possam competir com sucesso, potencializar a capacidade individual e coletiva mediante as práticas colaborativas para o alcance de objetivos, proporcionando alternativas de emprego, a diversificação de renda para as famílias, bem como a valorização e promoção da cultura e história locais, fatores que podem ser determinantes para a permanência das famílias no meio rural (DEL GROSSI; SILVA, 2002; BRUNETTI, 2006; FACCIN et al., 2009; ANDRADE, 2012). As principais motivações mencionadas para a participação na Rota das Salamarias foram: 
[...] disseminar, mostrar né, que se tu vir aqui e não me comprar nada eu não vou deixar de te mostrar tudo [...] [E1].

[...] o que me deixa feliz, [...] é tu poder receber as pessoas aqui e tu ver eles aqui numa alegria e logo depois trazendo mais gente [...] [E2].

[...] como é descendente de italiano a gente pensa de não deixar terminar a tradição [...] [E3].

[...] primeiro, eu acho que foi a parte financeira [...] [E4] (informações verbais).

De acordo com Liu et al. (2014), os benefícios econômicos são uma motivação importante e significativa para a maioria das pessoas que participam em atividades de base comunitária. Em contrapartida, Candiotto (2013) destaca que o crescimento econômico se mantém como principal ponto de interesse, embora se utilize o discurso da valorização cultural, a melhoria da qualidade de vida e a sustentabilidade.

Mas os fatores não econômicos, como enfatizar um senso de dever e orgulho podem ser usados como ferramentas para incentivar os moradores a se envolverem em atividades pró-ambientais e promoverem o bem-estar comum, como, a partir da perspectiva cognitiva, a construção de orientação de valor da comunidade e desenvolvimento de comprometimento emocional dos residentes, ou a partir da perspectiva estrutural, estabelecendo formas de orientar o comportamento dos moradores e melhorando suas práticas educativas (LIU et al., 2014). Também, para Park et al. (2012), os benefícios financeiros do desenvolvimento do turismo são cruciais para a construção de mais confiança social e cooperação nas comunidades.

Na categoria Relação entre as famílias integrantes foi possível verificar que a maior parte das famílias associadas já mantinha algum tipo de relação, mostrando uma dimensão estrutural do capital social da Rota das Salamarias, na qual, segundo Nahapiet e Ghoshal (1998), percebe-se o padrão geral de conexão entre os participantes:

[...] se conhece entre as famílias sim porque a gente se criou aqui todo mundo meio junto, meio perto, próximo, [...] nós somos vizinhos, então a gente já tinha o conhecimento das famílias [...] [E2].

[...] todos fazem parte da comunidade, [...] já todos se conheciam, as famílias que fazem parte da Rota [...] [E4] (informações verbais).

Para Hwang, Stewart e Ko (2012), os relacionamentos são construídos por meio de uma série de interações e podem exigir um período apropriado para serem percebidos como a construção de relacionamento. Por outro lado, a respeito de in- 
segurança e desconfiança para a criação da associação, inicialmente pode haver resistência ou reações locais negativas às iniciativas de desenvolvimento do turismo (HWANG; STEWART; KO, 2012).

[...] a população quase que toda foi meio contrária [...] a gente foi bastante criticado

[...] eles nunca levaram a sério né, só depois que começou a engrenar $[\ldots][\mathrm{E} 1]$.

[...] eu tenho certeza que a maioria das pessoas não acreditava [...] até nós sócios, nós tínhamos dúvidas, nós tínhamos medo [...] era uma coisa muito nova, [...] assustava muito [...] [E2] (informações verbais).

Porém, feedback e interação entre os participantes comunitários poderiam proporcionar um diálogo apreciativo necessário para a implementação de colaboração para o turismo, canalizando para a ação coletiva e levando a consequências positivas para a comunidade e para a viabilidade em longo prazo do turismo (HWANG; STEWART; KO, 2012).

Essas interações possuem elementos comuns como coerência e conectividade, cooperação, interdependência, autonomia, confiança, interatividade, colaboração, objetivos e valores compartilhados, cultura, comunhão, comunicação, associação, articulação, normas e benefícios coletivos (FACCIN et al., 2009). A boa relação entre os participantes é essencial para o alcance dos objetivos da Associação, verificando-se, sobre a relação das famílias e entre as famílias, o seguinte:

[...] eu classifico ela não ótima, mais do que isso, porque a gente se reúne uma vez por mês [...] e a participação é de todos [...] a gente sempre teve uma união, mas isso ela me ajuda muito na permanência dos meus filhos aqui, e isso eu te dou assim, por certeza, que senão, [...] os filhos, não teria mais nenhum aqui [...] [E2].

[...] cada reunião, todo mundo participa, decidem juntos o que vão fazer [...] precisa de mais mão de obra né, e se não há um envolvimento da família, uma pessoa sozinha não consegue fazer [...] acho que uniu mais [...] há mais comunicação [...] [E4] (informações verbais).

O desenvolvimento do turismo rural exige uma estreita interação entre os moradores locais por meio de confiança mútua, redes, normas e relações sociais, o que corrobora os pressupostos de Park et al. (2012), evidenciando a importância das rela- 
ções criadas entre os associados por meio das atividades coletivas mencionadas pelos entrevistados e contribuindo para a permanência das famílias nas propriedades rurais.

Na categoria Qualificação e aperfeiçoamento dos associados e projetos futuros da Associação, percebe-se que existe troca de conhecimento entre os associados:

[...] a gente sempre trabalha com uma parceria, [...] são cinco anos de Rota, a cada ano ela vai mostrando um amadurecimento, conhecimento de nós das famílias, que é por aí que a gente tem que trabalhar, é parceria, se não é parceria ela não anda [...] [E2] [...] um conversa com o outro [...] pra ver o que foi feito de diferente, o que vamos fazer diferente, então há sim uma troca de informação também né, tanto quanto de produtos quanto de outras coisas que vêm de fora [...] [E4] (informações verbais).

Mostra-se, assim, um exemplo de capital social, em que as relações são privilegiadas e transmitem conhecimento tácito, que é mais relevante para obter e manter vantagens competitivas, aumentando, dessa forma, o capital social, conforme ressalta Marti (2004).

Esse tipo de organização, como uma Associação para o desenvolvimento do turismo rural, precisa priorizar a qualificação e o aprendizado constantes de seus membros, a fim de promover a competitividade e incentivar a criatividade em atividades culturais como forma de preservar do patrimônio histórico, fomentar o lazer cultural e aumentar a autoestima das comunidades do meio rural (BRUNETTI, 2006; TOMAZONI, 2007). Assim, sobre a participação dos associados da Rota das Salamarias em cursos de aperfeiçoamento e viagens técnicas, observou-se o que segue:

[...] a gente foi ver novas Rotas, foi conhecer novas proprieda-
des e a gente dali, que a gente se conscientizou [...] [E2].
$[\ldots .$.$] reunião regional sobre turismo, [...] curso EMATER, pales-$
tras, o pessoal da vigilância, [...], mês passado uma pessoa da
própria BRF esteve duas noites dando umas considerações para
nós sobre o andamento da carne suína, do próprio salame, da
copa, vários, informações novas, não só de produção, mas num
todo [...] [E6] (informações verbais).

Nesse sentido, é necessário treinar e explicar à população local sobre os recursos, potencialidades e riscos da nova atividade, como a formação de custos, o uso de recursos naturais, as horas de trabalho necessárias e o carácter sazonal da nova atividade e como ela se encaixa com os ciclos de trabalho tradicionais. Também, visto que as atividades de turismo rural se baseiam em visão de longo prazo, requer-se nor- 
matização, capacitação e profissionalização delas (CZAJKOWSKI; CUNHA, 2010; OLIVEIRA; ZOUAIN, 2011; GASCÓN, 2013). Sobre projetos futuros compartilhados pelas famílias da associação e projetos para implementar a Rota como um todo, os entrevistados destacam o seguinte:

[...] esse projeto do asfalto, umas partes aí vão ser asfaltadas [...] [E1].

[...] nós vamos construir uma [...] agroindústria de chimias, [...] nesse mesmo projeto já deixar o espaço pra que seja feito pra fábrica de suco [...] acho que de momento seriam essas duas coisas [...] a agroindústria para as famílias [...] e o trajeto [...] [E2].

[...] as novas sinalizações, que a gente [...] tá trocando aos poucos, melhorando [...] [E6] (informações verbais).

Corroborando Del Grossi e Silva (2002), o fato de os produtores terem explorado cada vez mais diversos mercados, como artesanato, doces, bebidas, vinhos, salgados, carnes e derivados e lácteos e derivados, e, no caso da Rota das Salamarias, a implantação da agroindústria mencionada pelos entrevistados, possibilitarão a exploração desses mercados de acordo com as normas da Vigilância Sanitária.

Na categoria percepções dos participantes a respeito da Associação e dificuldades enfrentadas por ela, sobre se a propriedade está suficientemente organizada para receber turistas, verificou-se que:

[...] 100\% não [...] Hoje, mesmo como tudo que está ali eu te diria assim que a gente está com 50,60\% do que eu pretendo [...] a gente sempre depende de recursos próprios e somos todos pequenos proprietários, [...] então nós não temos condições de assim, de querer fazer um investimento grande, a curto prazo, porque daí a gente vai se comprometer [...] nós precisamos de incentivo, nós precisamos de uma ajuda [...] que daí depois aos poucos tu vai fazendo o restante [...] [E2] (informação verbal).

A disponibilidade de recursos como capital, espaço, instalações, equipamentos e mão de obra pode ser impactada pela dimensão estrutural do capital social, bem como pelo incentivo do Poder Público para o desenvolvimento do turismo rural, o que está de acordo com as pesquisas de Oliveira e Zouain (2011), Zhao, Ritchie e Echtner (2011) e Andrade (2012). No que se refere ao sucesso da Rota das Salamarias, entre as opções destacadas pelos entrevistados, encontra-se a cultura, a gastronomia, as belezas naturais, o acolhimento e as memórias. 
Demonstra-se, assim, que os valores, atitudes e crenças coletivos compartilhados pelos associados podem ter uma influência mais poderosa sobre seus comportamentos do que as normas e regras da comunidade (LIU et al., 2014), pressupondo-se aqui um exemplo de capital social cognitivo o qual, segundo Nahapiet e Ghoshal (1998), refere-se a recursos que representam visões compartilhadas, interpretações e sistemas de significados, como linguagem, códigos e narrativas. Quando questionados sobre se, hipoteticamente, saíssem da Associação, o que mudaria em termos competitivos, de conhecimento e qualidade, as respostas foram as seguintes:

[...] eu ia dar falta dessas reuniões, desses produtos deles, [...] agendamento das visitas que sempre me colocam [...] [E1]. [...] se hoje [...] terminasse a Rota, eu seria o primeiro a pegar a sacola e sair, [...] só com o pouco da agricultura, eu não vejo como nós permanecermos aqui, não tem como, não adianta, [...] é realidade, não se sobrevive [...] [E2].

[...] porque na Rota você sempre acompanha, uma coisa nova, sempre está mais a par dos acontecimentos, procura ao menos conhecer alguma coisa diferente para melhorar né, se você tá fora, pra casa qualquer coisa serve [...] [E3].

[...] a Rota das Salamarias é o que divulga o nosso produto [...] [E4].

[...] no sentido financeiro [...] [E6] (informações verbais).

Essa interação ou colaboração possibilita o desenvolvimento de vantagens competitivas sustentáveis, criando valor e características únicas, e entre os benefícios do desenvolvimento do turismo bem-sucedido se pode citar o orgulho em realizações da comunidade, o aumento de habilidades, competências e autoestima, e melhorias na segurança e nas interações sociais (FACCIN et al., 2009; MOSCARDO, 2012), mostrando um exemplo de capital social relacional que se trata de ativos criados e alavancados por meio das relações (NAHAPIET; GHOSHAL, 1998).

Sobre o que sentem ao literalmente abrir a casa para estranhos, os entrevistados expressaram que não há problemas em receber os turistas, pois estes agregam novos conhecimentos aos produtores, o que corrobora a descrição de turismo rural como atividade que oferece hospitalidade e vivência peculiar aos turistas (MINISTÉRIO DO TURISMO, 2010).

Percebem-se aqui os aspectos positivos do turismo no espaço rural, como a experiência proporcionada aos visitantes; o resgate da autoestima dos moradores do interior; a melhoria da infraestrutura dos acessos e das propriedades como um todo; a preservação de patrimônios naturais, rurais, culturais e históricos; bem como 
a geração de empregos e a diversificação da renda das famílias (BRUNETTI, 2006; ANDRADE, 2012).

Por outro lado, as principais dificuldades enfrentadas pela Associação mencionadas pelos entrevistados tratam da venda dos produtos fora das propriedades, visto que os produtos alimentícios não se encontram completamente de acordo com as normas da Vigilância Sanitária.

[...] com essas leis, com essas vigilâncias de hoje em dia, claro, eles estão no papel deles, tem que ter coisa boa, limpa, só que a gente está preocupado, que a gente, o que você faz pra comer aqui em casa, que acho que está limpo, porque a gente cuida, e faz pra consumo, [...] e você não pode mais vender fora, [...] já andaram pegando multa porque [...] tem que ter alguém que assine, [...] eles dizem o rótulo, acho que mais é pra imposto [...] mas daí você gasta bastante [...] você teria que produzir em grande quantidade [...] [E3].

[...] o nosso maior problema hoje é a legalização [...] dos produtos coloniais, então o projeto futuro [...] que está sendo visto, que é mais importante é essa casa específica pra chimias né, tudo dentro dos padrões exigidos pela vigilância sanitária né, que é para não ter problemas em participar de festivais, como a Expo Marau, esses né, que a gente só pode vender dentro da propriedade, para poder sair fora tem que estar legalizado, tem que ter uma lei municipal [...] [E4] (informações verbais).

Roque e Vivan (1999) citam alguns pontos fracos na gestão do turismo rural como, por exemplo, políticas públicas pouco desenvolvidas, linhas de créditos inexistentes ou inadequadas para a implantação das atividades e legislações inadequadas para a realidade rural. Esses são fatores que podem desestimular o desenvolvimento das atividades ligadas ao turismo rural dos associados.

[...] falta de [...] recursos para fazer coisas novas, grandes assim mais $[. .$.$] eu gostaria que nós pudéssemos [...] ter direito às ver-$ bas pra nós melhorarmos a estrutura da Rota [...] [E2].

[...] o Poder Público, a Prefeitura incentivou bastante no começo, era para continuar [...] [E3].

[...] teria que procurar mais recurso fora né, ajuda do governo no caso [...] [E4] (informações verbais).

Segundo Andrade (2012), o sucesso do turismo em uma região depende da participação mais ativa do Poder Público e de outros agentes fomentadores do turismo, pois todos os envolvidos na prática dessas atividades precisam de mais informa- 
ções para conhecê-las e desenvolvê-las, o que facilita a organização e a divulgação do negócio, e pode, assim, aumentar o leque de atrativos ofertados e oportunizar a participação do Poder Público na solução de problemas como a melhoria da infraestrutura básica.

Ainda, outro ponto fraco citado por Roque e Vivan (1999) na gestão do turismo rural pode ser a mão de obra despreparada para a prestação de serviço de turismo no espaço rural, conforme mencionado por um dos entrevistados:

[...] receber essas pessoas [...] é uma parte que a gente tem que trabalhar muito com as nossas famílias ainda né, [...] essa parte ainda ela está um pouquinho assim, de certas famílias, da associação, não por má vontade, mas talvez assim por uma timidez, por um receio ainda de conversar com as pessoas, então a gente está enfrentando essas dificuldades, mas eu tenho certeza assim que o conhecimento [...] de outras pessoas, e daqui a pouco um trabalho, uma palestra, [...] um curso, [...] enfim, pra melhorar [...] [E2] (informação verbal).

Dessa forma, é importante a qualificação da mão de obra relacionada aos empreendimentos turísticos, de modo a aproveitar melhor os potenciais da região e envolver a comunidade nas atividades turísticas rurais, formalizando as ações coletivas dos associados (ROQUE; VIVAN, 1999; DEL GROSSI; SILVA, 2002; CZAJKOWSKI; CUNHA, 2010; OLIVEIRA; ZOUAIN, 2011).

Além disso, com a introdução do ciclo de trabalho do turismo há uma reestruturação das tarefas domésticas e das tarefas envolvidas no turismo nas economias rurais, ou seja, essa nova atividade gera processos devidos a um aumento no trabalho doméstico, visto que essa necessária reestruturação do horário de trabalho dentro do grupo doméstico deveria ser estabelecida com vistas a um equilíbrio de esforços (GASCÓN, 2013), conforme relatam os entrevistados:

[...] aumentou o serviço, aumentou o compromisso, porque você tem que manter isso aqui melhor do que antes e não largar a outra coisa [...] pra não de repente não largar o que está com mais resultado, então estamos continuando, daí com mais serviço [...] [E3].

[...] porque [...] a gente não trabalha só com isso né, então a gente tem outras atividades né, então, não dá para botar 100\% aqui, mas procurar ficar o máximo né, recebendo as pessoas e produzir tudo o que a gente pode para oferecer [...] [E4] (informações verbais). 
Ainda faltam instrumentos jurídicos e legislação específica para a ativação do turismo no espaço rural; planos de desenvolvimento turísticos em níveis federal, estadual e municipal; ativação de programas de incentivo e esclarecimento para a implementação das atividades do turismo no espaço rural; legislação específica para a comercialização de produtos produzidos nas propriedades, havendo possibilidade de agregação de valor e permitindo a industrialização caseira dos produtos; selo de qualidade para a promoção de produtos, com indicação de proveniência; programas de divulgação; estabelecimento de planilhas de custo para gerenciar a propriedade; e contratação de profissionais da área de administração rural para dar suporte ao empresário para implementação de técnicas administrativas, contribuindo para o desenvolvimento do negócio (ROQUE; VIVAN, 1999; MINISTÉRIO DO TRABALHO, 2010). Essas estratégias podem contribuir para o crescimento e a manutenção das propriedades nas atividades de turismo rural na Rota das Salamarias.

\section{CONCLUSÃO}

Percebe-se que as famílias da Associação Rota das Salamarias compartilham projetos futuros, como, por exemplo, a criação de uma agroindústria, aspecto importante no funcionamento de uma rede colaborativa. Outra observação importante diz respeito à fala unânime dos seis entrevistados em não pensarem em deixar as propriedades e irem para a cidade, demonstrando que os resultados das atividades de turismo rural podem ser determinantes para a permanência dessas famílias no meio rural. Nota-se o sentimento de pertencimento, inclusive na linguagem não verbal dos entrevistados. Depois da questão financeira, a troca de experiências e o pertencimento a um grande grupo foram os principais ganhos observados, corroborando, assim, que o capital social é relevante para o desenvolvimento eficaz do turismo rural. Importante também salientar que, segundo os relatos, todas as propriedades mencionaram obter vantagem econômica, no entanto, nenhuma delas tem registros que comprovem tal resultado.

De acordo com o Plano de Desenvolvimento do Turismo do Rio Grande do Sul (2012; 2015), o turismo é transversal, característica que exige um esforço de integração para que fatores como infraestrutura de acesso, por exemplo, não sejam limitadores da atividade. Além disso, o alinhamento dos governos municipais com as instâncias de governança estaduais, regionais e municipais favorece a execução da política em todos os níveis do governo e, consequentemente, o desenvolvimento do 
setor. Isso pode se aplicar ao turismo rural e pode ser observado nas melhorias pretendidas pela Associação Rota das Salamarias.

Destaca-se, com base nos resultados, a necessidade de melhorias; uma sugestão útil para a Associação pode ser a profissionalização da gestão, realizando plano de ação e planejamento estratégico, para ter registros das melhorias e melhor visualização do crescimento, bem como para saber onde melhor podem ser investidos os recursos para se obterem melhores resultados.

Em síntese, entre os principais achados da presente pesquisa, destaca-se o fato de o turismo rural ser uma estratégia de desenvolvimento local que contribui para a geração de renda e para a manutenção das famílias em suas propriedades, fortalece o empreendedorismo familiar e amplia a relação entre as famílias que compõem a Rota, o que corrobora os pressupostos de Brunetti (2006), Czajkowski e Cunha (2010) e Andrade (2012), pois o turismo rural influencia os recursos das famílias rurais, ocasionando a melhoria da qualidade de vida.

Identifica-se a relevância do crescimento econômico, destacado por Candiotto (2013), e o capital social reconhecido no formato de interação social proporcionado pela referida Associação. Essa coesão social fundamenta a construção de vantagens competitivas sustentáveis, dado que o conhecimento é adquirido e transmitido a todos que fazem parte da rede de parceiros, gerando riquezas para as propriedades e para a região da qual fazem parte, como referido por Nahapiet e Ghoshal (1998), Marti (2004) e World Bank (2015).

Embora com dificuldades para aliar o tempo das atividades rotineiras da propriedade com o atendimento aos turistas, as famílias observam resultados positivos na atividade complementar, e percebem vantagens na sua manutenção, buscando, assim, aumentar os investimentos para qualificar seus produtos e serviços.

No que se refere às contribuições acadêmicas, este estudo corrobora para que novas pesquisas explorem a importância do capital social para o desenvolvimento do turismo rural. Destaca-se que, por abordar temas de capital social e turismo rural, que são temáticas relevantes para a sociedade e as políticas públicas, possa servir como fonte de interesse para novos acadêmicos que queiram se aprofundar nas temáticas.

Em nível gerencial, os achados desta pesquisa evidenciam informações relevantes para agricultores e gestores políticos, que podem tomar decisões mais assertivas no que se refere ao capital social e ao turismo rural. Neste estudo evidencia-se que as pessoas possuem uma forte influência no turismo rural, que traz benefícios para toda a comunidade local. 
Quanto às limitações da presente pesquisa, vinculam-se à participação de demais agricultores, já que se realizaram entrevistas com seis representantes de famílias agricultoras locais, bem como à questão da cultura rural local, a qual pode ter influenciado a presente pesquisa. Coerentemente, os dados não podem ser generalizados.

Nesse sentido, sugere-se uma análise mais abrangente, ampliando a amostragem dos entrevistados, bem como a realização de pesquisas quantitativas, visando mensurar a importância do capital social para o desenvolvimento do turismo rural. Como pesquisas futuras, sugere-se verificar a percepção de outros atores inseridos no contexto, assim como realizar a comparação dos achados desta pesquisa com outras redes de cooperação de diferentes regiões e setores, realizando-se entrevistas com representantes dessas outras organizações e empresas da região, o que poderia possibilitar a triangulação dos resultados e o consequente reforço dos achados da pesquisa, além de contribuir para a consecução do objetivo proposto nesta.

\section{REFERÊNCIAS}

ANDRADE, D. Turismo rural: análise dos resultados de um projeto de extensão no âmbito da comunidade. Observatório de Inovação do Turismo. Revista Acadêmica, Rio de Janeiro, v. 7, n. 4, abr. 2012.

BARDIN, L. Análise de conteúdo. Tradução Luís Antero Reto e Augusto Pinheiro. São Paulo: Edições 70, 2011.

BOCK, I. A. A.; MACKE, J. Desenvolvimento local e políticas públicas no turismo: o caso de uma rede colaborativa no sul do Brasil. In: INTERNATIONAL CONFERENCE ON TOURISM \& MANAGEMENT STUDIES, 1., 2001, Algarve. Anais... Algarve, 2001.

\section{BRUNETTI, R. A organização em rede e o turismo no espaço rural no Estado} do Paraná: o caso GETER - Grupo de Empreendedores do Turismo no Espaço Rural. 2006. Dissertação (Mestrado em Turismo e Hotelaria)-Universidade do Vale do Itajaí, Balneário Camboriú, 2006.

CANDIOTTO, L. Z. P. O discurso da viabilidade do turismo rural na agricultura familiar: o programa nacional de turismo rural na agricultura familiar (PNTRAF) e o papel do Estado do Paraná no contexto. Revista de Cultura e Turismo, v. 7, n. 2, jun. 2013. 
CZAJKOWSKI, A.; CUNHA, S. K. Organização e coordenação da rede de cooperação em aglomerados de turismo rural. Revista Turismo Visão e Ação - Eletrônica, v. 12, n. 1, p. 92-113, jan./abr. 2010.

DEL GROSSI, M. E.; SILVA, J. G. O novo Rural: uma abordagem ilustrada. Londrina:Instituto Agronômico do Paraná, 2002. v. 1. Disponível em:

$<$ http://www.iapar.br/modules/conteudo/conteudo.php?conteudo=868>. Acesso em: 28 jun. 2015.

FACCIN, K. et al. Capital social: recurso estratégico para o desempenho de redes organizacionais. Ariús, Campina Grande, v. 15, n. 2, p. 9-23, jul./dez. 2009.

FACCIN, K.; GENARI, D.; MACKE, J. Mensuração do Capital Social nas Redes Colaborativas Vitivinícolas da Serra Gaúcha. Organização \& Sociedade, v. 20, n. 65, p. 303-320, abr.jun. 2013.

FLICK, U. Introdução à pesquisa qualitativa. Tradução Joice Elias Costa. 3. ed. Porto Alegre: Artmed, 2009.

GASCÓN, J. The limitations of community based tourism as an instrument of development cooperation: the value of the social vocation of the territory concept. Journal of Sustainable Tourism, v. 21, i. 5, p. 716-731, 2013.

HWANG, D.; STEWART, W. P.; KO, D. Community Behavior and Sustainable Rural Tourism Development. Journal of Travel Research, v. 51, i. 3, p. 328-341, 2012.

IBGE. Censos Demográficos Brasileiros de 1940, 1991, 2000 e 2010. Disponível em: http://downloads.ibge.gov.br/downloads_estatisticas.htm>. Acesso em: 20 ago. 2014.

JOHANNESSON, G. P.; SKAPTADOTTIR, U. D.; BENEDIKTSSON, K. Coping with social capital? The cultural economy of tourism in the north. Sociologia Ruralis, v. 43, i. 1, p. 3-16, 2003.

JONES, S. Community-based ecotourism: the significance of social capital. Annals of Tourism Research, v. 32, i. 2, p. 303-324, 2005.

LIU, J. et al. The role of social capital in encouraging residents' pro-environmental behaviors in community-based ecotourism. Tourism Management, v. 41, p. 190201, 2014. 
MARCONI, M. A.; LAKATOS, E. M. Fundamentos de metodologia científica. 7. ed. São Paulo: Atlas, 2010.

MARTI, J. M. V. Social capital benchmarking system: profiting from social capital when

building network organizations. Journal of Intellectual Capital, v. 5, i. 3, p. 426442, 2004.

MINISTÉRIO DO TURISMO. Diretrizes para o Desenvolvimento do

Turismo Rural. 2003-2007. Disponível em: <http://www.turismo.gov.br/turismo/ diretrizes_desenvolvimento_turismo >. Acesso em: 15 ago. 2014.

MINISTÉRIO DO TURISMO. Turismo rural: orientações básicas. 2. ed. Brasília, DF: Ministério do Turismo, 2010.

MOSCARDO, G. Building Social Capital to Enhance the Quality-of-Life of Destination Residents. In: UYSAL, M.; PERDUE, R.; SIRGY, M. J. Handbook of Tourism and Quality-of-Life Research: Enhancing the Lives of Tourists and Residents of Host Communities, International Handbooks of Quality-of-Life. Springer, 2012. chapter 24, p. 403-421.

NAHAPIET, J.; GHOSHAL, S. Social Capital, intellectual capital, and the organizational advantage. Academy of Management Review, v. 23, i. 2, p. 242-266, 1998.

OLIVEIRA, C. T. F.; ZOUAIN, D. M. Turismo rural e agricultura familiar: desafios e perspectivas para o campo. Observatório de Inovação do Turismo. Revista Acadêmica,

Rio de Janeiro, v. 6, n. 2, jun. 2011.

PARK, D. B. et al. Factors influencing social capital in rural tourism communities in South Korea. Tourism Management, v. 33, p. 1511-1520, 2012.

PLANO DE DESENVOLVIMENTO DO TURISMO DO RIO GRANDE DO SUL: 2012-2015. Rio de Janeiro: FGV Projetos, 2012. Disponível em: <http://www.sindetur-rs.com.br/site/novo/doc/20140205124002plano_de_desenvolvimento_turismo_rs.pdf $>$. Acesso em: 15 ago. 2014. 
ROQUE, A. M.; VIVAN, A. M. Turismo no espaço rural: uma estratégia para a nova gestão rural brasileira. Organizações Rurais e Agroindustriais. Revista de Administração da UFLA, v. 1, n. 1, jan./jun. 1999.

SILVEIRA, M. A. N. da; SALVAGNI, J. Turismo, relações de trabalho e a reorganização do espaço rural. Oficina do Historiador, Porto Alegre: EPHIS: PUCRS, p. 1018-1034, maio 2014.

TEIXEIRA, A. R.; SOUZA, M.; ROBE, E. A. A emergência do associativismo enquanto forma de gestão de roteiros turísticos rurais. In: PORTUGUEZ, A. P.; SEABRA, G.; QUEIROZ, O. T. M. M. (Org.). Turismo, espaço e estratégias de desenvolvimento local João Pessoa: Editora Universitária da UFPB, 2012.

QUEIROZ, O. T. M. M. (Org.). Turismo, espaço e estratégias de desenvolvimento local. João Pessoa: Ed. UFPB, 2012.

TOMAZONI, E. L. Educação Profissional em Turismo. Cria-se Mercado pela Formação? Turismo em Análise, v. 18, n. 2, p. 197-219, nov. 2007.

WORLD BANK. What is social capital? 2015. Disponível em: <http:// web.worldbank.org/WBSITE/EXTERNAL/TOPICS/EXTSOCIALDEVELOPMENT/EXTTSOCIALCAPITAL/0,,contentMDK:20185164 menuPK:418217 pagePK:148956 piPK:216618 theSitePK:401015,00.html>. Acesso em: 03 jul. 2015.

YIN, R. K. Estudo de caso: planejamento e métodos. 4. ed. Porto Alegre: Bookman, 2010.

ZHAO, W.; RITCHIE, J. R. B.; ECHTNER, C. M. Social capital and tourism entrepreneurship. Annals of Tourism Research, v. 38, i. 4, p. 1570-1593, 2011.

Como citar este artigo:

ABNT

Jaqueline dos Santos et al. Capital social e turismo rural em uma Associação do Norte do Rio Grande do Sul: um estudo da Rota das Salamarias. RACE, Revista de Administração, Contabilidade e Economia, Joaçaba: Ed. Unoesc, v. 16, n. 2, p. 547-572, maio/ago. 2017. Disponível em: <http://editora.unoesc.edu.br/index.php/ race $>$. Acesso em: dia/mês/ano. 
Jaqueline dos Santos et al.

\section{APA}

Santos, J. dos, Melara, F., Severo, E. A., \& Macke, J. (2017). Capital social e turismo rural em uma Associação do Norte do Rio Grande do Sul: um estudo da Rota das Salamarias. RACE, Revista de Administração, Contabilidade e Economia, 16(2), 547-572. Recuperado em dia/mês/ano, de http://editora.unoesc.edu.br/index.php/race 